\title{
O CINEMA DOCUMENTÁRIO E OS ARQUIVOS DA MEMÓRIA
}

\section{THE DOCUMENTARY CINEMA AND THE MEMORY FILES}

\author{
Mírian ALVES ${ }^{1}$; Dúnya AZEVEDO²
}

Resumo: A partir do documentário intitulado Rua Santa Fé, dirigido pela chilena Carmen Castillo, e da noção de memória para diferentes pensadores contemporâneos, esse artigo investiga o cinema documentário como possibilidade de registro e reconhecimento mnemônicos. O ponto de partida são as reflexões propostas por Paul Ricoeur em torno das noções de memória e esquecimento. $\mathrm{O}$ que se percebe, com esse estudo, é que o cinema documentário, como um arquivo, pode explicitar e compartilhar com os espectadores as marcas impressas no corpo de seu diretor. Além disso, em seu processo de produção, o documentário pode ainda desencadear aquilo que Ricoeur nomeia como o "pequeno milagre da memória feliz".

Palavras-chave: Imagens-lembrança; Esquecimento de reserva; Documento; Testemunho.

Abstract: Considering the movie "Calle Santa Fe" (Santa Fe Street, 2007), directed by the chilean filmmaker Carmen Castillo, and the notion of memory, proposed by different contemporary philosophers, this article investigates the documentary cinema as a possibility of mnemonic recording and recognition. The starting point is the reflection, proposed by Paul Ricoeur, around the notions of memory and forgetting. What this study reveals is that the documentary cinema, as a file, can explain and share with the audience the marks printed on the body of the filmmaker. In addition, its production process can still trigger what Ricoeur names as the "little miracle of happy memory."

Keywords: Images of memory; Reserve Oblivion; Document; Testimony.

\footnotetext{
${ }^{1}$ Doutora em Estudos Literários pela Universidade Federal de Minas Gerais (UFMG) e professora no Departamento de Linguagem e Tecnologia do CEFET-MG / miriansousalves@ gmail.com.

${ }^{2}$ Doutoranda em Comunicação Social pela Universidade Federal de Minas Gerais (UFMG) e professora da Universidade Fumec, em Belo Horizonte, MG, Brasil. dunya.azevedo@ gmail.com
} 


\section{míDiA \\ ecot DiAno}

\section{Introdução}

Salvar o passado, preservar a memória e resgatar a tradição são intensas preocupações das últimas décadas do século $\mathrm{XX}$, período que assistiu a um interesse crescente pela discussão em torno do tema da memória. Em várias áreas do conhecimento, a memória tornou-se um objeto de estudo e uma tarefa ética. O objetivo deste artigo é investigar um aspecto específico do cinema documentário: sua capacidade de dar visibilidade à memória de seus produtores (como um arquivo de imagens), ao mesmo tempo em que remodela os acontecimentos que compõem sua narrativa. Procuraremos investigar as relações estabelecidas entre a memória (individual e coletiva) e o cinema documentário, a partir de uma reflexão do filme documentário Rua Santa Fé, dirigido pela cineasta chilena Carmen Castillo.

Após 33 anos de exílio, Carmen Castillo, viúva de Miguel Enriquez, secretário geral do Movimento de Esquerda Revolucionária (MIR) no Chile, revisita, com sua câmera, os espaços físicos de Santiago, dos quais esteve distante desde outubro de 1974, ano em que seu marido foi assassinado por representantes da ditadura militar do general Augusto Pinochet. Grávida, ela sobrevive, é presa e posteriormente expulsa de seu país. Em seu documentário intitulado Rua Santa Fé (BEL/CHI/FR, 2007), nome da rua onde morava com Miguel Enriquez, ela procura reunir os fragmentos desse passado e dar a esse um novo sentido.

Enquanto analisava as produções em cinema e em vídeo de Jean-Luc Godard, o pesquisador francês Philippe Dubois (2004) destaca, em seu texto "A paixão, a dor e a graça: notas sobre o cinema e o vídeo dos anos 1977-1987”, que no decorrer dessa década diversos campos da criação artística, incluindo aí o cinema e o vídeo, assistiram a um deslizamento da inocência à impureza, do desejo e esperança à dor, da plenitude à incerteza, ou seja, uma oscilação de um sentido a outro da palavra paixão. Parte-se assim da crença, da plenitude e do desejo de agir provocados pela paixão amorosa ao outro sentido da palavra paixão, aquele que recupera sua raiz etimológica.

Para Dubois, entre o final da década de 1970 e 1980, passamos, assim, da paixão amorosa (do sujeito apaixonado, como viva afecção) à paixão dolorosa (ao modo da Paixão de Cristo). "No curso da década de 80, vivemos a passagem de uma paixão à 


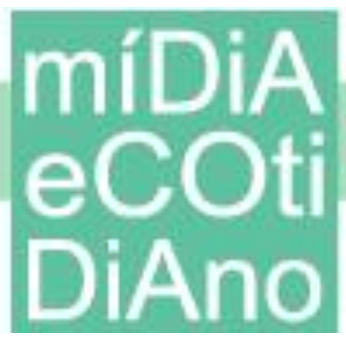

outra”, explica o pensador. Ao assimilar a perda da inocência, as produções artísticas só podem se constituir a partir do recolhimento dos restos. Após a retirada dos deuses e o fim da crença em uma possível plenitude, restou aos artistas reunir os restos. Daí o fato de o fragmento e a desilusão surgirem como marcas das produções desse período histórico.

Embora lançado no início do século XXI, o documentário dirigido pela chilena Carmen Castillo, Rua Santa Fé, aponta diretamente para tal oscilação. Ao narrar os acontecimentos que a afastaram de uma crença no sistema político chileno, a partir de meados dos anos 70, a voz em off da narradora busca compreender a violência vivida por ela naquele período de ditadura e o impacto dessa violência na identidade que tenta construir, a partir de tal esfacelamento. A memória, tema do documentário, surge aí como um artifício que visa viabilizar a construção da nova identidade da diretora.

Revisitar a rua onde se deu esse deslizamento da fé à dor coloca-se assim como um ato de rememoração, e o dispositivo do documentário, escolhido por Castillo como mecanismo construtor de lembranças, aparece como possibilidade de produção de sentido a partir da total ausência desse, deixada pela lembrança da brutalidade e da violência a qual foi exposta durante as ações que deram início à ditadura militar no país, o que ocorreu 34 anos antes da produção do filme documentário.

De fato, vários são os autores que apontam para o surgimento de uma cultura e uma política da memória a partir de acontecimentos históricos como o Holocausto, a queda do Muro de Berlim, o fim das ditaduras, o fim do apartheid na África do Sul e a dissolução do bloco comunista no leste europeu. O crítico alemão Andreas Huyssen (2014) alerta para o fato de tais eventos tornarem evidente o papel das memórias traumáticas. Para o autor, faz-se necessário investigar as maneiras como esses acontecimentos transformam nossa experiência espaço-temporal.

Huyssen chama atenção para a valorização do tema da memória e sua evocação também nos países latino-americanos a partir do fim das ditaduras: no Brasil, na Argentina e no Paraguai, nas décadas de 1970 e 1980, e no Chile, em 1990. Inicia-se aí um processo de reparação às vítimas, dando voz às testemunhas e abrindo arquivos proibidos. 
Como nos mostra Dubois, a arte depara-se, a partir daí, com a impossibilidade de ignorar a perda da crença gerada pelas desilusões políticas decorrentes desses movimentos. A perda da fé não se restringe assim à política; a sensação é resvalada às produções artísticas que apontam, de forma cada vez mais veemente, para a descrença e para a perda de unidade e plenitude.

Andreas Huyssen defende que os estudos sobre memória precisam se alinhar à luta por direitos humanos, para evitar que o olhar para o passado seja "autoindulgente e sem vitalidade política”. Vista dessa forma, a memória seria elemento libertador das vítimas para quem o esquecimento e a falta de punição seriam inaceitáveis. É o caso do grupo formado pelas Madres de Plaza de Mayo ou pelo H.I.J.O.S. (Hijos e Hijas por la Identidad y la Justicia contra el Olvido y el Silencio) da Argentina ${ }^{3}$.

Diante de tal emergência da memória como uma forte inquietação políticocultural das sociedades ocidentais, novos questionamentos são apontados em torno da busca da verdade histórica de um fato passado. Como parte dessas reflexões, a noção de testemunho é colocada em questão, pois o testemunho funciona como uma espécie de guardião da memória. A problematização em torno das noções de testemunho e sua ligação com a memória questiona o estatuto de verdade e nos obriga a refletir sobre as relações entre passado e presente.

Pretendemos com essa reflexão, perceber de que forma a produção do documentário Rua Santa Fé elucida, ao mesmo tempo, a memória e o esquecimento dos acontecimentos traumáticos vividos por Castillo, nos anos 1970, no Chile. Além disso, pretende-se perceber o cinema documentário a partir da noção de rastro apresentada pelo pensador francês Paul Ricoeur. Para o autor, como o cinema, o rastro situa-se sempre no presente e lida com a dicotomia de ser positividade e presença; ao mesmo tempo em que funciona como signo de uma causa ausente. Assim, o rastro será pensado a partir de sua relação de representação, enquanto o esquecimento e a lembrança serão

\footnotetext{
${ }^{3}$ HIJOS (Hijos e Hijas por la Identidad y la Justicia contra el Olvido y el Silencio) é uma organização de direitos humanos da Argentina. Fundada em 3 de novembro de 1994, é composta por filhos de ex-presos políticos, exilados, desaparecidos, à época da ditadura argentina. Seu objetivo é a luta contra a impunidade dos crimes cometidos na ditadura militar naquele país.
} 


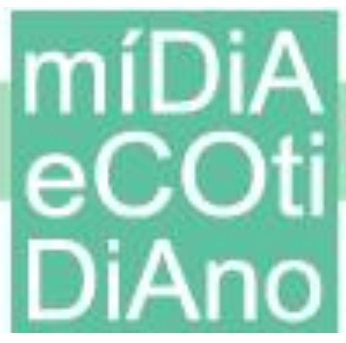

associados à ideia da experiência vivida.

Em seu documentário, Carmen Castillo volta a Santiago e revisita a casa onde viveu na clandestinidade com seu marido e sua filha até o dia em que, em confronto com a polícia, seu marido foi morto e ela ficou gravemente ferida depois da explosão de uma granada. A partir de suas lembranças e de depoimentos dos testemunhos que viveram o drama daquele momento histórico, a diretora, faz apelo a uma memória coletiva que se entrelaça com sua memória individual, através das quais se delineia a história política de um país. Assim, o passado se restitui e sua intimidade se transforma em uma investigação documental que mescla imagens de arquivo, entrevistas, depoimentos e sua própria narração.

A narrativa em off, produzida pela autora, anos após o recolhimento das imagens, parece preencher as lacunas deixadas pelo esquecimento necessário à continuidade de sua trajetória. Já as imagens editadas tentam reunir fragmentos de sua memória costurados às imagens recolhidas por outros personagens que participaram do mesmo horror histórico por ela enfrentado.

Embora se trate do fim de uma história amorosa, a desintegração da família da cineasta parece ter acompanhado a dissolução também da unidade política e de um projeto de nação, ameaçado pelo início da ditadura no Chile. Enquanto registro de tais acontecimentos, o documentário testemunha e ao mesmo tempo ressignifica, trinta e quatro anos depois, os acontecimentos vividos na rua Santa Fé.

Sabemos que a memória é sempre uma negociação entre a memória individual e a memória coletiva. Essa, por sua vez, envolve as memórias individuais, mas não se confunde com elas. Ao mesmo tempo em que a memória individual se reporta a pontos de referência que são fixados pela sociedade, nossas lembranças individuais estão ligadas a nossas experiências individuais. Isto é, não lembramo-nos senão do que vimos, vivemos ou sentimos.

Em suma, o indivíduo possui duas memórias que estão entrelaçadas: a memória interior (interna, pessoal, autobiográfica) e a memória exterior (social, histórica), bem mais ampla. A primeira se apoia na segunda, pois toda história de nossa vida faz parte da história em geral. (HALBWACHS, 1990, p. 55). E a memória do trauma é sempre 


\section{míDiA

uma negociação entre a memória individual e a memória coletiva.

O testemunho pode ser então pensado como parte de uma complexa política da memória. Como aponta Seligmann (2008), o testemunho, no caso de situações traumáticas, possui um papel de aglutinador de um grupo de pessoas que constroem a sua identidade a partir dessa identificação com a memória coletiva.

\section{Gesto testemunhal}

Em suas reflexões sobre o gesto testemunhal em situações de trauma, Seligmann afirma que a necessidade do testemunho se apresenta como condição de sobrevivência para as pessoas que viveram essas situações. É a reconstrução de um espaço simbólico que confere uma nova dimensão aos fatos antes enterrados: uma retemporalização do fato antes embalsamado (SELIGMANN, 2008, p. 69).

No entanto, o autor ressalta casos em que se parte do princípio da impossibilidade do testemunho, formulada por Dori Laub (1995), que lembra que o Holocausto foi um "evento sem testemunha”. Primo Levi (1990), assim como Laub, um sobrevivente dos campos de concentração nazistas, embora não considere o testemunho do trauma impossível, acentua o seu caráter limitado. Na memória do trauma há sempre uma "irrealidade", diz Seligmann (2008), uma espécie de eclipse, próprio do caráter paradoxal da temporalidade psíquica no gesto testemunhal.

Ao questionar os vizinhos que testemunharam o assassinato de seu marido, Carmem descreve: "Tenho uma recordação, que não sei se corresponde à realidade, de me arrastarem na calçada, na esquina da (rua) São Francisco (...)". Essa sensação de inverossimilhança dos fatos parece ligar-se à melancolia do trauma, que permanece como um corpo estranho naquele que sobrevive (SELIGMANN, 2008, p. 69). O excesso e a violência do evento que causou o trauma provocam a incompletude do que se sabe e deixam um rastro de irrealidade.

O testemunho está, assim, intrinsecamente ligado à memória. Mas longe de ser um arquivo, a memória é o que engendra atos de rememoração. Ela é social e não parte apenas do nosso aparelho cognitivo. Há que se considerar o caráter subjetivo da memória, as manipulações conscientes e inconscientes que o interesse, a afetividade, o 
desejo, a inibição e a censura exercem sobre a memória individual (LE GOFF, 2003). Por isso, ela é seletiva e se situa na tensão entre o presente e o ausente. Há, portanto, uma relação dialética entre memória e esquecimento.

Diante da impossibilidade do testemunho ou de sua limitação, a imaginação é convocada como auxílio na narração do trauma. O testemunho oscila entre a literalidade do trauma e sua dimensão imaginária. Recordamos dos eventos passados através de uma imagem mental. O imaginário, próprio do ato testemunhal, é uma forma de apreensão do real, assim como a memória. Se há então uma impossibilidade da literalidade testemunhal, a possibilidade do testemunho está sempre em parte ligada à ficção.

Assim como a memória, a narrativa também tem um caráter seletivo. É impossível lembrar-se de tudo e é impossível também tudo narrar, pois, como se sabe, o passado é inapreensível. Mesmo na narrativa histórica, há sempre o trabalho da imaginação na interpretação dos dados documentais pelo historiador. Citando Ricoeur:

\begin{abstract}
A ideologização da memória é possibilitada pelos recursos de variação que o trabalho de configuração narrativa oferece. As estratégias do esquecimento enxertam-se diretamente nesse trabalho de configuração: pode-se sempre narrar de outro modo, suprimindo, deslocando as ênfases, refigurando diferentemente os protagonistas da ação assim como os contornos dela. (RICOEUR, 2008, p. 455).
\end{abstract}

Freud afirma que "o choque, o trauma fere, separa, corta ao sujeito o acesso ao simbólico, em particular à linguagem" (apud GAGNEBIN, 2009, p. 51). Narrar o trauma é então essa tarefa paradoxal de narrar o inenarrável, de representar o irrepresentável. O testemunho pressupõe uma ligação com o real, com o referente; mas diante das limitações da memória, da impossibilidade do testemunho e da inapreensão da verdade histórica, como não cair em um relativismo em que tudo se torna verdade?

Como esclarece Shoshana Felman, Freud reconhece pela primeira vez na história da cultura que não é necessário ser dono da verdade para testemunhar sobre ela, que "o discurso enquanto tal é testemunhal sem o saber e aquele que fala constantemente testemunha uma verdade que, apesar disso, continua a lhe escapar. (FELMAN, 2000, p. 27). Como ato de fala performático, o testemunho não se apresenta como relato acabado dos eventos. Tanto na literatura, como na psicanálise e na história, o que testemunha passa a ser aquele que gera a verdade dos fatos no processo discursivo (ibid, p. 28). 


\section{míDiA

O documento e o arquivo

Tradicionalmente, o cinema documentário tem afinidades com o documento e a própria palavra "documentário" destaca essa relação. Mas é preciso investigar a noção de documentário, pois muitas críticas feitas a esse tipo de cinema hoje são baseadas na sua relação com a verdade ou a representação fiel do real, tarefa que foi também atribuída ao documento. Mas uma nova maneira de pensar o documento pela chamada "nova história" chamou atenção do filósofo e historiador Michel Foucault, nos anos 1960, quando elabora sua teoria sobre as noções de documento e de monumento e afirma: "a história é o que transforma os documentos em monumentos" (FOUCAULT, 2004, p. 8).

Os documentos do passado foram preservados como produtos de uma sociedade cujo intuito era impor, ao futuro, determinada imagem de si própria. (LE GOFF, 2003, p. 535-538). O que transforma os documentos em monumentos é a sua utilização pelo poder. Um documento revela determinadas imagens do passado e omite outras. Cabe ao historiador estabelecer um sentido aos dados documentais da história. A sobrevivência de determinados documentos depende de julgamentos e análises humanas, em nome, sobretudo, de causas humanas.

Com o processamento massivo de dados, o documento ganha novo estatuto e deixa de ser visto como valor por si próprio para ganhar novo sentido na organização da série, na relação com os que o precedem e os que o sucedem. (...) “é o seu valor relativo que se torna objetivo e não a sua relação com uma inapreensível substância real"'(FURET apud LE GOFF, 2003, p. 532). Assim, como não há fato histórico puro, mas sim como construção do historiador, não há documento bruto e objetivo.

A tarefa primordial da história, segundo Foucault, não é interpretar o documento, nem determinar se diz a verdade, mas sim, elaborá-lo: "Ela o organiza, recorta, distribui, ordena e reparte em níveis, estabelece séries, distingue o que é pertinente do que não é, identifica elementos, define unidades, descreve relações" (FOUCAULT, 2004, p.07). É esse conjunto de operações que traduz o que Foucault denominou como "crítica do documento". Cabe ao historiador (ou ao artista) o papel de 
desmontagem e remontagem dos fragmentos, como é o próprio funcionamento da memória, fragmentária e incompleta. Carmen Castillo, ao buscar as imagens do passado e os arquivos, relaciona-os com outras imagens, documentos e depoimentos, num gesto de restituição de um passado que lhe escapa.

\section{O documentário e a noção de rastro sensível}

Ao recuperar a discussão feita por Henri Bergson, em "Matéria e Memória", Ricoeur lembra que o corpo pode ser pensado como órgão de ação e não de representação e o cérebro como centro organizador desse sistema que age. Assim, para Bergson (2006), a lembrança "pura" pode ser vista como o estado virtual da representação do passado (anterior à sua vinda sob a forma de lembrança-imagem). Bergson, citado por Ricoeur (2008, p. 442) explica:

[ um presente qualquer, desde seu surgimento, já é seu próprio passado; pois como se tornaria passado se não tivesse se constituído ao mesmo tempo em que era presente. Como nota Deleuze: "Existe aí como que uma posição fundamental do tempo, assim como o paradoxo mais profundo da memória: o passado é 'contemporâneo' do presente que ele foi. Se o passado tivesse de esperar para não mais ser, se ele não fosse passado imediatamente e agora, 'passado em geral', nunca poderia se tornar o que ele é, nunca seria este passado. [...] O passado é "o que não age mais" [...] Essa impotência radical da 'lembrança pura' nos ajudará precisamente a compreender como ela se conserva em estado latente. A palavra "inconsciente" pode então ser proferida em conjunto com "impotência". A cadeia das implicações completa-se com um último termo: é possível conceder, para as lembranças que ainda não tiveram acesso, pela recordação, à luz da consciência, o mesmo tipo de existência que atribuímos às coisas que nos rodeiam quando não as percebemos. É esse sentido do verbo "existir" que está assim implicado na tese da latência e da inconsciência das lembranças conservadas do passado. (RICOEUR, 2008, p.442)

Para Bergson, devir não significa passagem, mas duração da memória. Haveria, portanto, para o autor, uma permanência das imagens e não um esquecimento seguido de reconhecimento mnemônico, como coloca Paul Ricoeur (2008, p.443). Em sua reflexão, Ricoeur aponta contradições presentes no pensamento bergsoniano:

O próprio Bergson não afirma que vamos buscar a lembrança onde ela está, no passado? Mas toda sua empreitada consiste em substituir a pergunta "onde?" pela pergunta "como?": "só restituirei [à lembrança] seu caráter de 
lembrança reportando-me à operação pela qual a evoquei, virtual, do fundo de seu passado". Talvez aí esteja a verdade profunda da anamnesis grega: buscar é esperar reencontrar. (RICOEUR, 2008, p.443)

De que forma o cinema documentário lida com tais questões? Como coloca Jean-Louis Comolli (2008, p.113), “o cinema torna sensível, perceptível e, às vezes, diretamente visível o que não se vê: a passagem do tempo nos rostos e nos corpos", o que faz do cinema um instrumento privilegiado para uma reflexão acerca do esquecimento e da lembrança, processos relacionadas à ideia de sobrevivência enquanto duração, ou seja, ao próprio movimento rumo ao envelhecimento e à morte.

Por outro lado, o cinema documentário pode novamente ser colocado como objeto privilegiado a uma reflexão acerca do rastro enquanto registro documental, inscrição, prova material de uma experiência vivida, já que, como o rastro, lida com a dicotomia de estar sempre no tempo presente, embora se refira ao passado. Tomemos então Comolli (2008, p. 112-13):

\begin{abstract}
Paradoxo do cinema: o traço inscrito é sempre passado, mas carrega sempre com ele o presente da inscrição. Eterno presente. [...] as imagens e os sons que ela manifesta aos meus sentidos inscrevem-se no presente da minha tela mental. Presente absoluto da percepção. Partilha do presente: o que se inscreve na tela e o que eu, espectador, estou vivendo, estão, de certa forma, em uma relativa grande coincidência. No entanto, o aqui-e-agora da projeção reproduz o aqui-e-agora da inscrição verdadeira apenas como engodo. Engodo essencial. Aquela ilusão que funda o cinema. [...] Como o espectador deixaria de saber que, entre a tomada e a projeção, todo um labirinto de tempo e de materiais foi percorrido? Ele sabe disso, o que não o impede de perceber o movimento do filme no presente da projeção. Há engodo, livremente consentido, quando percebo no presente não a realidade atual da projeção, mas aquela, não atual, da inscrição verdadeira. Opero uma colagem espaciotemporal que traz de volta à tela e na duração da projeção um lugar e um tempo que eram os da cena. (COMOLLI, 2008, p.112,113)
\end{abstract}

Talvez possamos aqui fazer um paralelo entre o trabalho da inscrição (forma de duração ou permanência das afecções) que, para Paul Ricoeur, conteria o segredo do rastro mnemônico e o trabalho do documentário, enquanto inscrição fílmica. O mesmo processo de imprimir no sujeito essas marcas que, para Ricoeur, apontariam para o início de uma 'verificação existencial', é percorrido pela máquina cinematográfica durante a elaboração do filme documentário. Basta saber se os rastros da experiência vivida, materializados em imagens internas (de localização duvidosa) seriam 


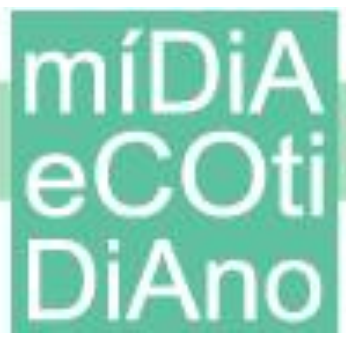

representações tanto quanto os realizados pela máquina cinematográfica ou se poderiam ser vistos como ações cerebrais, em detrimento da ideia de representação, como colocado por Bergson.

Para Paul Ricoeur, há pelo menos três espaços reservados aos rastros, enquanto inscrições. O primeiro seria o espaço dos arquivos, reservado pelas instituições sociais ao rastro documental; o segundo seria o cérebro, reservado pela organização biológica ao rastro cortical e o terceiro espaço, que mais interessa ao autor e a esse artigo, seria o espaço da persistência das impressões primeiras, marcas afetivas que permanecem em nosso espírito.

A sobrevivência das imagens, para Ricoeur, constitui uma forma fundamental de "esquecimento profundo", denominado pelo autor como "esquecimento de reserva" (Ricoeur, 2008, p. 436). Acredito que a experiência do reconhecimento, colocada por Ricoeur como o "pequeno milagre da memória feliz", é o que pode ser visto ao longo das imagens registradas pela câmera de Carmen Castillo, no filme documentário Rua Santa Fé (Chile, 2007). Ao revisitar os espaços físicos de Santiago, a autora em sua narração chama atenção para a importância do espaço exterior:

[...]"acho que os lugares são importantes. Nós deveríamos recuperar todos os lugares. Porque se contar às pessoas que não viveram isso, quando se leva ao lugar físico, real, concreto, aqui mataram Sedolin Lausich, aqui deram um tiro na cabeça de Isidro Áries. Neste lugar, neste lugar, na torre, quase todos que passaram aqui estão desaparecidos. Isso adquire outras dimensões". (CASTILLO, CHILE, 2007)

Ricoeur mostra que o reconhecimento propriamente mnemônico consiste na exata superposição da imagem presente na mente e do rastro psíquico, também chamado de imagem, deixado pela impressão primeira. Para o autor, essa representação presente de uma coisa passada seria como um "pequeno milagre de múltiplas facetas".

Para Ricoeur, que neste ponto concorda com Bergson, a inscrição nada mais é que a sobrevivência por si da imagem mnemônica contemporânea da experiência originária. Nesse sentido, o filme documentário Rua Santa Fé não se coloca simplesmente como um arquivo externo ou um rastro documental. A relação existente entre a diretora do documentário e os espaços percorridos por sua câmera dariam a essas 
imagens a capacidade de se sobrepor, de maneira mais ou menos exata, às "impressões primeiras" de Castillo.

As imagens de Rua Santa Fé, neste sentido, colocam-se como imagenslembrança, capazes de transformar a relação dos espectadores com seus próprios esquecimentos de reserva. À medida que percorre os espaços do passado de Castillo, as imagens exibidas expõem-se como rastros mnemônicos capazes de tocar também as imagens-lembrança dos espectadores, independente da maior ou menor semelhança entre o "esquecimento de reserva" desses e as imagens ali expostas.

Essa “"viúva-heróica' cega, surda e quase muda que, após o exílio, se desloca, pelos subúrbios de Roma, Estocolmo, Londres, Toronto e Paris em andanças sem visão, na mesma repetição de códigos" - como coloca a locução em off da documentarista em Rua Santa Fé - revisita, ao longo das filmagens, os espaços de sua infância, que permaneceram latentes em sua memória. Dessa forma, as imagens por ela produzidas chegam ao espectador, revestidas da potência que adquirem ao longo do filme: a de serem imagens-lembrança.

Como coloca a narração em off feita pela documentarista de Rua Santa Fé, "precisamos lutar contra o esquecimento. Uma ditadura, a ditadura chilena é uma máquina de esquecimento". A inscrição fílmica aí, enquanto rastro, surge como um gesto de resistência a essa máquina de esquecimento. A esse respeito, retomemos Comolli (2008, p. 214-15):

A máquina cinematográfica produz sombra tanto quanto luz, fora-de-campo tanto quanto campo. Talvez por ser máquina? Por que uma parte de impensado e de incontrolado subsiste nela e em nós? Se as máquinas são elas mesmas apenas parcelas do mundo, elas só podem confessar, sem denegação possível, que não o têm por inteiro em seu poder. Qualquer máquina é limite e nos impõe a consciência desse limite. Há um ponto cego da máquina de ver. Filmar se organizou historicamente como algo que gira em torno desse ponto cego. Contra as falsas certezas e as falsas inocências do visível, contra a própria "naturalidade" do visível, ver, no cinema, é começar por não ver, aceitar não "ver tudo", não "tudo de uma vez", não "tudo ao mesmo tempo"; ver segundo uma organização temporal e espacial, uma decupagem, um corte e uma montagem do mundo. (COMOLLI, 2008, p.214,215) 
Aliás, o caráter de incompletude desta montagem ou desse processo de rememorar a partir de andanças por espaços já habitados é um dos pontos centrais de Rua Santa Fé. Há uma imagem no filme que pode traduzir essa ideia. O plano é composto pelo portão da casa de número 725 da rua Santa Fé, onde a diretora vivia com sua família antes do exílio. Há um pequeno furo no portão por onde a cineasta e sua amiga espiam o pátio da casa. Tal espaço visto através do pequeno furo no portão envelhecido parece fazer referência ao próprio processo de construção do documentário de Castillo, que só encontra ou revê os espaços mediados por relatos inexatos, gastos pelo próprio esquecimento.

Mais à frente, o documentário recupera a mesma imagem do furo no portão e, em seguida, expõe a parede da casa com a tinta descascada. Há camadas de tinta nesta parede que impedem a diretora de ver o espaço tal qual ela o conhecia antes de 1974. "Está tudo muito diferente", diz Castillo ao entrar na casa. "Por que mudaram as paredes? Sim, as paredes eram brancas", diz em tom reticente.

Inexatas e parciais - já que respeitam a própria limitação da decupagem imposta pelo cinema - tais imagens colocam-se, entretanto, como camadas de produção do vivido. Por trás delas, não há a história real vivida por Castillo, da mesma forma que o passado não se esconde atrás do presente. Trata-se antes de um processo cíclico e contínuo que aponta para a simultaneidade de passado e presente ou do processo de esquecimento e reconhecimento.

\section{Conclusão}

A partir dessa reflexão, é possível afirmar que os filmes documentários, como arquivos, podem guardar no tempo as histórias afetivas individuais e coletivas, além de compartilhá-las com os espectadores. Longe de um resgate íntegro do passado, essas imagens acionam algo desse passado que é da ordem da imaginação, dos afetos, da percepção e da memória.

É importante enfatizar que no filme documentário Rua Santa Fé, a militância de Carmen Castillo no MIR (Movimento de Esquerda Revolucionária) não é uma questão central. Sua participação na resistência contra a ditadura de Augusto Pinochet - que 


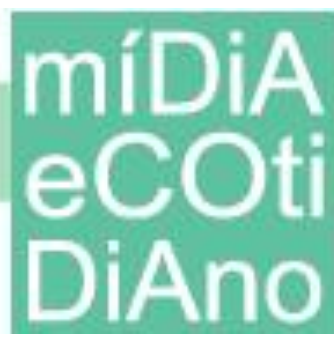

durou de 1973 a 1990 - e sua vida na clandestinidade com Miguel Enríquez, entra como pano de fundo para uma narrativa que pretende reconstruir um espaço simbólico e dar novo sentido a uma experiência traumática vivida por ela no passado. Seu gesto testemunhal se apresenta como condição de sobrevivência para a cineasta. São fragmentos de memória que apaziguam e apontam para uma necessidade de superação do trauma.

Ao promover um encontro da cineasta Carmen Castillo com a arquitetura de sua cidade de infância, em Santiago, e com os objetos da casa onde viveu, antes do exílio decorrente da ditadura militar chilena, o documentário Rua Santa Fé desencadeia o que Ricoeur nomeia de "pequeno milagre da memória feliz".

Essa especificidade pode estender-se às narrativas de outras produções audiovisuais contemporâneas. Para a cineasta, a memória individual e coletiva pode ser facilmente acionada pelas relações travadas entre ela, a arquitetura da cidade, os objetos da casa e as pessoas envolvidas na produção do filme documentário. Já para os espectadores, os estímulos visuais e sonoros do filme podem facilmente desencadear essa mesma memória.

\section{Referências}

BERGSON, Henri. Matéria e Memória. Ensaio sobre a relação do corpo com o espírito. São Paulo: Ed. Martins Fontes, 2006.

COMOLLI, Jean-Louis. Ver e poder. A inocência perdida: cinema, televisão, ficção, documentário. Tradução de Augustin de Tugny, Oswaldo Teixeira e Ruben Caixeta. Belo Horizonte: Ed. UFMG, 2008.

DIDI-HUBERMANN, Georges. O que vemos, o que nos olha. Tradução de Paulo Neves. São Paulo: Editora 34, 1998.

DUBOIS, Philippe. Cinema, vídeo, Godard. Tradução de Mateus Araújo Silva. São Paulo: Cosac Naify, 2004.

FELMAN, Shoshana. Educação e crise, ou as vicissitudes do ensino. In: NETROVSKI, Arthur e SELIGMANN SILVA, Márcio (orgs.) Catástrofe e representação. São Paulo: Escuta, 2000.

FOUCAULT, Michel. A arqueologia do saber. Rio de Janeiro: Forense Universitária, 2004.

GAGNEBIN, Jeanne. Lembrar escrever esquecer. São Paulo: Ed. 34, 2009. 
http://diversitas.fflch.usp.br/files/active/0/aula_8.pdf.

HALBWACHS, Maurice. A memória coletiva. São Paulo: Vértice, 1990.

HUYSSEN, Andreas. Culturas do passado-presente: modernismos, artes visuais, políticas da memória. Rio de Janeiro: Contraponto, 2014.

LAUB, D. Truth and testimony: the process and the struggle. In Caruth, C. (org.). Trauma: explorations in memory. Baltimore: Johns Hopkins University Press, 1995.

LE GOFF, Jacques. História e Memória. Campinas, São Paulo, Ed. Unicamp, 2003.

LEVI, Primo. Os afogados e os sobreviventes. Rio de Janeiro: Paz e Terra, 1990.

NUNES, B. Narrativa histórica e narrativa ficcional. In: PRADO JR., B.; PESSANHA, J. A.; NEVES, L. F. B. et al. Narrativa: ficção e história. Rio de Janeiro: Imago, 1988.

RICOEUR, Paul. A memória, a história, o esquecimento. Tradução de Alain François [et al.]. Campinas: UNICAMP, 2008.

Fontes, 2010c.

Tempo e narrativa: o tempo narrado. Tomo III. São Paulo: WMF Martins

SELIGMANN SILVA, Márcio. Narrar o trauma: as questões dos testemunhos de catástrofes históricas, 2008. Disponível em http://www.scielo.br/pdf/pc/v20n1/05. Acesso em 15/04/2015.

\section{Referência filmográfica}

RUA Santa Fé. Direção: Carmen Castillo. Bélgica/Chile/França, 2007. Dvd (163 min), son, color. Título original: Calle Santa Fe. 